\title{
Post-anoxic myoclonus
}

\author{
Pavis Laengvejkal MD, Parunyou Julayanont MD, Drew Payne DO
}

\section{INTRODUCTION}

Myoclonus is a movement disorder characterized by involuntary, sudden, brief muscle jerks caused by muscular contraction (positive myoclonus) or inhibition (negative myoclonus). ${ }^{1,2}$ Myoclonus is generally a medical sign and not a diagnosis. It can occur in multiple disorders. A short differential diagnosis list includes anoxic brain injury, multiple sclerosis, Parkinson's disease, subacute sclerosing panencephalitis, and Creutzfeldt-Jakob disease. One way to classify the etiologies is through review of the clinical presentation and comorbid conditions. This article presents a review of anoxic brain injury related myoclonus. Post-anoxic myoclonus (PAM) can develop in either acute or chronic phase. Acute PAM occurs within hours after hypoxic event; chronic PAM (LanceAdams syndrome) develops in survivors several days to weeks after the episodes of brain hypoxia.

\section{Clinical manifestations ACUTE PAM}

Acute PAM can develop from one hour to several days after anoxic events, and it occurs in $20-37 \%$ of comatose survivors from cardiopulmonary arrest. . $^{3,4}$ Myoclonus can be observed in various parts of the body, such as subtle facial twitching, rhythmic nystagmus, or low-amplitude multifocal muscle twitching. ${ }^{5}$ The majority of acute PAM develops within 24 hours after the hypoxic episodes. ${ }^{4,6}$ Acute PAM can be classified as focal/multifocal myoclonus and myo-

Corresponding author: Pavis Laengvejkal MD Contact Information: Pavis.Laengvejkal@ttuhsc.edu DOI: 10.12746/swrccc 2014.0106.078 clonic status epilepticus (MSE), which can be considered convulsive status epilepticus. ${ }^{4,6-8}$ Patients with MSE always have a comatose state. . $^{3,9}$ Some specific stimuli, such as tactile stimuli, tracheal suctioning, nail-bed pressure, trigeminal tactile stimuli or auditory stimuli, can trigger myoclonus. , $^{7,10-12}$

\section{Chronic PAM (LANCe-Adams syndrome)}

In 1963, Lance and Adams described four patients who developed myoclonus after cardiopulmonary arrest. In these patients myoclonus was stimulated by active muscular contraction; therefore, it was called action or intention myoclonus (Lance-Adams syndrome). ${ }^{13}$ Often additional stimuli, such as auditory stimuli, tactile stimuli, passive/active movement, coordination or anxiety can trigger myoclonus. ${ }^{13-16}$ Patients may develop negative myoclonus (postural lapses) concomitantly with positive myoclonus. ${ }^{17}$ The defining characteristic in chronic PAM is the onset. Chronic PAM develops days to weeks after hypoxic events. Cerebellar dysfunction, such as gait ataxia, dysmetria, slurred speech, usually coexists with myoclonic movement. Unlike acute PAM, patients with chronic PAM must regain consciousness following hypoxic events. ${ }^{3,15}$ Chronic PAM is more likely caused by respiratory arrest, such as an acute asthmatic attack, than cardiac arrest. $9,14,15$

\section{Pathophysiology ACUTE PAM}

The pathophysiology of acute PAM is poorly understood. Acute post-anoxic myoclonus can be caused by either cortical or brainstem damage. ${ }^{4,18,19}$ One report evaluated 64 patients 72 hours after cardiac arrest with somatosensory evoked potentials 
(SEP) and/or electroencephalograms (EEG). Cortical generated myoclonus was reported in $24(38 \%)$ of these patients. ${ }^{4}$ There is a report of spinal generated myoclonus presenting with abdominal myoclonus in a post-cardiac arrest patientt. ${ }^{20}$ The various EEG patterns associated with myoclonic episodes include bursts of generalized synchronous spike, polyspike activity, and burst suppression pattern. ${ }^{7,18,19}$ The epileptiform discharges from EEG reported in some acute PAM patients support the hypothesis that acute PAM may represent an ictal phrase of epileptic seizure. $^{7}$

The pathophysiology of stimulus-sensitive acute PAM remains inconclusive. However, short-lived neuronal hyperexcitability between motor cortex and posterior parietal cortex, which is a major multimodal sensory integrative part of a brain, may partially explain this phenomenon. ${ }^{12}$ In brain computed tomography (CT), cerebral edema and hypodensities in deep white matter, cerebellum, thalamus and cortical watershed areas were found more frequently in patients who developed myoclonus than those who had no myoclonus. ${ }^{3}$ Post-mortem examination showed typical cortical laminar necrosis from layers 3-5, hippocampal neuronal loss with reactive gliosis, diffuse loss of Purkinje cells in the cerebellum and diffuse neuronal loss in the globus pallidus and the putamen. ${ }^{3,19}$

\section{Chronic PAM}

The pathogenesis of chronic PAM is not entirely known. Myoclonus can originate from cortical, subcortical and/or brainstem areas.,21,22 Cortical generated myoclonus is more common than subcortical or brainstem reflex myoclonus. It predominantly develops in areas of the body with large cortical representation, such as facial and distal extremity muscles. Cortical myoclonus is highly action-induced and stimulus sensitive. The EEG findings include epileptic activities, sharp/slow waves, or a suppression-burst pattern. The SEP may demonstrate giant potentials which are compatible with hyperexcitability of the sensorimotor cortex. ${ }^{2,23}$
Brainstem generated myoclonus (reticular reflex myoclonus) usually presents with more generalized jerks mainly affecting axial and proximal muscles. Patients may demonstrate jerks with neck flexion or shoulder elevation along with trunk and knee extension. ${ }^{1,24}$ The EEG findings are variable, but cortical EEG events are not time-locked to the electromyographic (EMG) events. Unlike in the cortical myoclonus, the SEPs in brainstem myoclonus are not enlarged. ${ }^{1,2}$ If the cranial nerve muscles are involved, the signals on EMG of the lower cranial nerve musculatures (sternocleidomastoid and trapezius) usually precede the EMG signals from upper cranial nerve muscles (masseter, orbicularis oris), limbs muscles and cortical spike on EEG. ${ }^{24}$

Imaging studies of 12 patients with chronic PAM revealed four patients with unremarkable imaging, four patients with mild cortical and cerebellar atrophy, three patients with small vessel infarction, and one patient with two focal lesions in the right cerebellar hemisphere. ${ }^{15}$ With PET imaging, patients with chronic PAM have glucose hypermetabolism in the ventrolateral thalamus and pontine tegmentum relative to controls. ${ }^{25}$ In one animal model, the Purkinje cells at the cerebellar vermis appeared to be more vulnerable to global ischemia when compared with other areas. The Purkinje fibers from this area usually project to fastigial nuclei which innervate a large number of structures in the reticular system and thalamus including ventrolateral thalamic nuclei. ${ }^{26}$ The findings of vermal Purkinje cell damage after ischemic events in an animal model and the glucose hypermetabolism of ventrolateral thalamus may be linked to the pathophysiology of chronic PAM. ${ }^{18}$

Patients with chronic PAM have a lower level of serotonin in CSF. Damage to serotonin-containing neurons from a hypoxic event may explain the pathophysiology of chronic PAM. ${ }^{27}$ In addition to serotonin, gamma-aminobutyric acid (GABA) may have a role in generating chronic PAM. Clonazepam can improve myoclonus in patients with Lance-Adams syndrome. ${ }^{15,28}$ In animal studies, administration of GABA reuptake inhibitors (guvacine or nipecoic acid) reduced myoclonus scores in postanoxic rats. ${ }^{29}$ 


\section{DIAGNOSIS}

\section{ACUTE PAM}

The diagnosis of acute PAM is based on clinical symptoms of myoclonus in patients who recently survived cardiopulmonary arrest. The time frame to develop this condition is usually within, but not limited to, 24 hours after ischemic events. In MSE, a comatose state is one of the core clinical features. It is very important to monitor patients with EEG in order to detect epileptiform discharges. In stimulus-sensitive acute PAM, multi-modal sensory stimuli during EEG monitoring may increase the possibility in detecting of epileptiform discharges from the EEG. ${ }^{12}$

\section{Chronic PAM}

Chronic PAM is a rare condition without unique diagnostic criteria and can be challenging to diagnose. Chronic myoclonic movements in an awake patient recovering from an anoxic brain event are typically used for clinical diagnosis. Brain MRI or CT scans may help rule out other possible causes of myoclonus, but do not confirm the diagnosis. Imaging may demonstrate evidence of diffuse neuronal injury, such as multiple lacunar infarcts and white matter changes. ${ }^{30}$ In addition, it is important to note that sedation can lead to misinterpretation of an early state of chronic PAM as acute PAM, which has poorer prognosis. Thus the assessment of PAM should be made off sedation. . $^{9,31,32}$

\section{Prognosis}

\section{ACUTE PAM}

Patients with focal myoclonus have better prognosis than MSE. In a retrospective cohort study, eight of $47(17 \%)$ patients with acute focal PAM had moderate to good recovery on the Glasgow Outcome Scale; only 1 of $32(3 \%)$ patients diagnosed with MSE made a good recovery. ${ }^{4}$ The prognosis of MSE is extremely poor as $62-100 \%$ of patients died after a diagnosis of MSE. In the pooled results of 134 cases of acute PAM, $119(88.8 \%)$ died, 11 (8.2\%) remained in a per- sistent vegetative state and $4(3.0 \%)$ survived without a vegetative state. ${ }^{6}$ The majority of survivors were highly dependent or remained in persistent vegetative state. ${ }^{3,6,8,32}$ However, there were some reports of MSE patients who eventually recovered with a good neurological outcome. ${ }^{33,34}$

\section{Chronic PAM}

Unlike acute PAM, patients with chronic PAM survive with a more favorable outcome. Often their myoclonus gradually improves over several years until some patients can eventually discontinue antimyocIonic medications. ${ }^{15}$ These neurological deficits usually improve or resolve with time. Some patients may have minor neurological deficits, such as mild upper motor neuron weakness of one or more limbs, slightly reduced visual acuity, gaze evoked nystagmus, upward gaze palsy, or slow tongue movement. Most of the patients can walk with/without assistance. ${ }^{15}$ Despite the fact that there were some patients who developed seizure, it was not a long term sequelae in most cases. Seizure was resolved within one year in each case of new onset seizure after the event. ${ }^{15}$ Patients with chronic PAM had no grossly intellectual impairment after long term follow up; however, some of them demonstrated a mild degree of memory, language and perceptual impairment on extensive neuropsychological assessment. ${ }^{14,15}$

\section{TREATMENT ACUTE PAM}

Even though MSE is considered a part of convulsive status epilepticus, anticonvulsive drugs generally used to treat status epilepticus, such as intravenous phenytoin, valproate, phenobarbital or benzodiazepines, are usually ineffective in MSE. ${ }^{3,35}$ Bolus dose of intravenous propofol $(1.5 \mathrm{mg} / \mathrm{kg}$ body weight) followed by continuous infusion ( $1 \mathrm{mg} / \mathrm{kg}$ body weight/ hour) was reported to be effective in ceasing myoclonus and epileptiform discharge, and also maintaining the cessation of MSE. However, successful cessation of MSE with propofol did not change the grave prognosis of MSE. ${ }^{16}$ 


\section{Chronic PAM}

The majority of patients with chronic PAM spontaneously improve in months to years. Some patients can eventually stop antimyoclonic medications. ${ }^{36}$ Valproate was widely reported to be effective in reducing myoclonus. ${ }^{15,37-39}$ The mechanism of valproate is still unclear; augmentation of GABA level in central nervous system (CNS) may be the therapeutic effect of valproate in attenuating myoclonus. Hepatotoxicity, pancreatitis, and thrombocytopenia are serious adverse effects of valproate.

In addition, efficacy of clonazepam in treatment of chronic PAM has also been reported. ${ }^{15,28}$ Its mechanism in reducing myoclonic symptom remains elusive, but it may also be related to its ability to increase GABA level in CNS. It is important to consider its effect on CNS depression and its consequences (falling risk, cognitive impairment), especially when prescribing this medication in the elderly.

Chronic PAM was found to be associated with low cerebrospinal fluid level of serotonin and its metabolite 5-hydroxyindoleacetic acid (5-HIAA). Thus L-5-hydroxytryptophan (L-5-HTP), a precursor of serotonin, was studied to be an effective treatment for chronic PAM. ${ }^{27,38,40}$ Persistent euphoria and diarrhea are frequent side effects of L-5-HTP. Carbidopa, a peripheral decarboxylase inhibitor, is usually prescribed with L-5-HTP to prevent nausea and vomiting. In a report of 122 cases with chronic PAM, 24 of 47 (51\%), 10 of $22(45 \%)$, and 17 of $43(40 \%)$ patients treated with clonazepam, valproate, and L-5-HTP, respectively, had significant improvement of myoclonus. ${ }^{28}$

In the past decade, levetiracetam, a new antiepileptic medication which could inhibit glutamate transmission, has also been reported effective in the treatment of chronic PAM. ${ }^{17,36}$ It is important to note that the efficacy of these medications is the result of case reports and case series. Thus a double-blind randomized controlled trial is needed to confirm efficacy in the treatment of chronic PAM.
Other residual neurological deficits should be considered in these patients. Ataxia and negative myoclonus in chronic PAM increase the risk of falling, thus ambulatory and balance training are important to reduce falling incidence and further complications. Sliding board transfer may be used to reduce falling risk. ${ }^{41}$ Patients with slurred speech also may require speech therapy.

\section{Conclusion}

Post-anoxic myoclonus is a movement disorder occurring after hypoxic brain events. Myoclonus in acute PAM is sometimes considered as an ictal phase of epileptic seizure. It is crucial to monitor patients with EEG in order to detect of epileptiform discharges before and after treatment. Myoclonic status epilepticus usually responds poorly to antiepileptic medications generally used for status epilepticus; however, it consistently responds to propofol. The prognosis of acute PAM is grave. On the contrary, chronic PAM (Lance-Adams syndrome) is a rare disease developing several days to weeks after hypoxic events. After regaining consciousness, these patients develop intentional myoclonus which sometimes coexists with cerebellar dysfunction. Evaluation of chronic PAM must be done after cessation of sedatives. Unlike acute PAM, the prognosis of chronic PAM is very good with eventual spontaneous recovery of myoclonus. Even though there is no well-designed clinical trial, valproate, clonazepam, levetiracetam and L-5 hydroxytryptophan/carbidopa are usually prescribed to attenuate myoclonus in patients with this condition. Rehabilitation interventions should be run in parallel with medication in cases with cerebellar impairment.

In conclusion, post-anoxic myoclonus has different clinical features, according to the onset of symptoms, conscious level of patients and severity of the hypoxic events. It is crucial to recognize and distinguish between acute PAM and chronic PAM (Lance-Adams syndrome), since they have exceedingly different prognosis and treatment. 
Comparison of acute and chronic PAM

\begin{tabular}{|c|c|c|}
\hline & Acute PAM & Chronic PAM \\
\hline Causes & Cardiac arrest $>$ respiratory arrest & Respiratory arrest > cardiac arrest \\
\hline Onset & $\begin{array}{l}1 \text { hour to several days, most occur } \\
\text { within } 24 \text { hours after events }\end{array}$ & Days to weeks after events \\
\hline Consciousness & Comatose state in MSE & $\begin{array}{l}\text { Good consciousness (assessment after } \\
\text { cessation of sedatives) }\end{array}$ \\
\hline $\begin{array}{l}\text { Myoclonus and } \\
\text { related features }\end{array}$ & $\begin{array}{l}\text { - Reticular reflex myoclonus } \\
\text { (generalized, axial and proximal mus- } \\
\text { cles) } \\
\text { - Focal/multifocal cortical myoclonus }\end{array}$ & $\begin{array}{l}\text { - Cortical myoclonus (distal limbs, facial } \\
\text { muscles) > reticular reflex myoclonus } \\
\text { (generalized, axial and proximal muscles) } \\
\text { - Intention induced myoclonus } \\
\text { - Concomitant cerebellar dysfunction (gait } \\
\text { ataxia, dysmetria, slurred speech) }\end{array}$ \\
\hline Pathology & $\begin{array}{l}\text { - Severe cortical necrosis } \\
\text { - Diffuse loss of Purkinje cells in cere- } \\
\text { bellum } \\
\text { - Diffuse neuronal loss in the globus } \\
\text { pallidus and putamen } \\
\text { - More related to epileptic discharges }\end{array}$ & $\begin{array}{l}\text { - Prominent Purkinje cells loss at } \\
\text { cerebellar vermis } \\
\text { - Small white matter infarction } \\
\text { - Decrease level of serotonin and GABA in } \\
\text { CNS } \\
\text { - Rarely associated with epilepsy }\end{array}$ \\
\hline Prognosis & $\begin{array}{l}\text { - Extremely poor in MSE }(62-100 \% \text { died } \\
\text { or survived with persistent vegetative } \\
\text { state) } \\
\text { - } 17 \% \text { of patients with acute focal PAM } \\
\text { had moderate to good recovery on } \\
\text { Glasgow Outcome Scale }\end{array}$ & $\begin{array}{l}\text { - Good prognosis } \\
\text { - Gradual improvement of myoclonus } \\
\text { - Most of the patients can walk with/ } \\
\text { without assistance. } \\
\text { - No grossly intellectual impairment in } \\
\text { most cases (mild cognitive impairment in } \\
\text { some cases) }\end{array}$ \\
\hline Treatment & $\begin{array}{l}\text { - Propofol is effective in stopping and } \\
\text { maintaining the cessation of myoclonus. } \\
\text { - Phenytoin, valproate, phenobarbital } \\
\text { and benzodiazepines are ineffective. }\end{array}$ & $\begin{array}{l}\text { - Valproate, clonazepam, L-5-hydroxy- } \\
\text { tryptophan/Carbidopa, levetiracetam } \\
\text { were reported to be effective. } \\
\text { - No randomized controlled trials } \\
\text { - Ambulatory and balance training } \\
\text { - Speech therapy in cases with dysarthria }\end{array}$ \\
\hline
\end{tabular}


Author Affiliations: Pavis Laengvejkal and Parunyou Julayanont are residents in the Department of Neurology at TTHUSC. Drew Payne is a resident in Internal Medicine at TTUHSC.

Submitted: $1 / 16 / 2014$

Accepted: 4/1/2014

Reviewers: Jongyeol Kim MD

Published electronically: 4/15/2014

Conflict of Interest Disclosures: None

\section{REFERENCES}

1. Rivest J. Myoclonus. Can. J. Neurol. Sci. 2003;30 Suppl $1:$ S53-8.

2. Caviness JN, Brown P. Myoclonus : current concepts and recent advances. Lancet Neurol. 2004;3:598-607.

3. Wijdicks EF, Parisi JE, Sharbrough FW. Prognostic value of myoclonus status in comatose survivors of cardiac arrest. Ann. Neurol. 1994;35(2):239-43.

4. Bouwes A, van Poppelen D, Koelman JHTM, et al. Acute posthypoxic myoclonus after cardiopulmonary resuscitation. BMC Neurol. 2012;12:63.

5. Faught E. Clinical presentations and phenomenology of myoclonus. Epilepsia. 2003;44 Suppl 1:7-12.

6. Hui ACF, Cheng C, Lam A, Mok V, Joynt GM. Prognosis following Postanoxic Myoclonus Status epilepticus. Eur. Neurol. 2005;54(1):10-3.

7. Van Cott AC, Blatt I, Brenner RP. Stimulus-sensitive seizures in postanoxic coma. Epilepsia. 1996;37(9):868-74.

8. Celesia GG, Grigg MM, Ross E. Generalized status myoclonicus in acute anoxic and toxic-metabolic encephalopathies. Arch. Neurol. 1988;45(7):781-4.

9. English W, Giffin NJ, Nolan JP. Myoclonus after cardiac arrest: pitfalls in diagnosis and prognosis. Anaesthesia. 2009;64(8):908-11.

10. Young GB, Gilbert JJ, Zochodne DW. The significance of myoclonic status epilepticus in postanoxic coma. Neurology. 1990;40(12):1843-8.

11. Fernández-Torre JL, González-Rato J, Martínez-Martínez M. Acute stimulus-sensitive postanoxic myoclonus: description of a case. Clin. EEG Neurosci. 2005;36(3):199-201.

12. Fernández-Torre JL, Hernández-Hernández MA. Acute stimulus-sensitive postanoxic myoclonus: the importance of sensory stimulation in comatose patients. Clin. EEG Neurosci. 2012;43(4):312-4.

13. Lance JW, Adams RD. The syndrome of intention or ac- tion myoclonus as a sequel to hypoxic encephalopathy. Brain. 1963;86:111-36.

14. Harper SJ, Wilkes RG. Posthypoxic myoclonus (the Lance-Adams syndrome) in the intensive care unit. Anaesthesia. 1991;46(3):199-201.

15. Werhahn KJ, Brown P, Thompson PD, Marsden CD. The clinical features and prognosis of chronic posthypoxic myoclonus. Mov. Disord. 1997;12(2):216-20.

16. Thömke F, Weilemann SL. Poor prognosis despite successful treatment of postanoxic generalized myoclonus. Neurology. 2010;74(17):1392-4.

17. Krauss GL, Bergin, Kramer RE, Cho Y-W, Reich SG. Suppression of post-hypoxic and post-encephalitic myoclonus with levetiracetam. Neurology. 2001;56(3):411-412.

18. Venkatesan A, Frucht S. Movement disorders after resuscitation from cardiac arrest. Neurol. Clin. 2006;24(1):123-32.

19. Madison D, Niedermeyer E. Epileptic seizures resulting from acute cerebral anoxia. J. Neurol. Neurosurg. Psychiatry. 1970;33(3):381-6.

20. Legriel S, Stang M-B, Merceron S, Cronier P, Troche G. Ongoing Abdominal Status Myoclonus in Postanoxic Coma. Neurocrit. Care. 2011;16(1):136-138.

21. Brown P, Thompson PD, Rothwell JC, Day BL, Marsden CD. A case of postanoxic encephalopathy with cortical action and brainstem reticular reflex myoclonus. Mov. Disord. 1991;6(2):139-44.

22. Hallett M. Phisiology of Human Posthypoxic Myoclonus. Mov. Disord. 2000;15:8-13.

23. Cassim F, Houdayer E. Neurophysiology of myoclonus. Neurophysiol. Clin. Neurophysiol. 2006;36(5-6):281-91.

25. Hallett M, Chadwick D, Adam J, Marsden CD. Reticular reflex myoclonus: a physiological type of human post-hypoxic myoclonus. J. Neurol. Neurosurg. Psychiatry. 1977;40(3):253-64.

25. Frucht SJ, Trost M, Ma Y, Eidelberg D. The metabolic topography of posthypoxic myoclonus. Neurology. 2004;62(10):187981.

26. Welsh JP, Yuen G, Placantonakis DG, et al. Why do Purkinje cells die so easily after global brain ischemia? Aldolase C, EAAT4, and the cerebellar contribution to posthypoxic myoclonus. Adv. Neurol. 2002;89:331-59.

27. Magnussen I, Dupont E, Engbaek F, de Fine Olivarius B. Post-hypoxic intention myoclonus treated with 5-hydroxy-tryptophan and an extracerebral decarboxylase inhibitor. Acta Neurol. Scand. 1978;57(4):289-94.

28. Frucht $\mathrm{S}$, Fahn $\mathrm{S}$. The clinical spectrum of posthypoxic myoclonus. Mov. Disord. 2000;15 Suppl 1:2-7.

29. Jaw SP, Nguyen B, Vuong QT, Trinh T, Nguyen M, Truong DD. Effects of GABA uptake inhibitors on posthypoxic myoclonus in rats. Brain Res. Bull. 1996;39(3):189-92.

30. Polesin A, Stern M. Post-anoxic myoclonus: a case presen- 
tation and review of management in the rehabilitation setting. Brain Inj. 2006;20(2):213-7.

31. Sandroni C, Cavallaro F, Callaway CW, et al. Predictors of poor neurological outcome in adult comatose survivors of cardiac arrest: a systematic review and meta-analysis. Part 1: patients not treated with therapeutic hypothermia. Resuscitation. 2013;84(10):1310-23.

32. Fugate JE, Wijdicks EFM, Mandrekar J, et al. Predictors of neurologic outcome in hypothermia after cardiac arrest. Ann. Neurol. 2010;68(6):907-14.

33. Arnoldus EP, Lammers GJ. Postanoxic coma: good recovery despite myoclonus status. Ann. Neurol. 1995;38(4):697-8.

34. Datta S, Hart GK, Opdam H, Gutteridge G, Archer J. Post-hypoxic myoclonic status: the prognosis is not always hopeless. Crit. care Resusc. 2009;11(1):39-41.

35. Thömke F, Marx JJ, Sauer O, et al. Observations on comatose survivors of cardiopulmonary resuscitation with generalized myoclonus. BMC Neurol. 2005;5:14.

36. Venot M, Weiss N, Espinoza S, et al. Improvement of early diagnosed post-anoxic myoclonus with levetiracetam. Intensive Care Med. 2011;37(1):177-9.

37. Liron L, Chambost M, Depierre P, Peillon D, Combe C. [Effectiveness of valproic acid for postanoxic action myoclonus (Lance-Adams syndrome)]. Ann. Fr. Anesth. Reanim. 1998;17(10):1247-9.

38. Carroll WM, Walsh PJ. Functional independence in post-anoxic myoclonus: contribution of L-5-HTP sodium valproate and clonazepam. Br. Med. J. 1978;2(6152):1612.

39. Rollinson RD, Gilligan BS. Postanoxic action myoclonus (Lance-Adams syndrome) responding to valproate. Arch. Neurol. 1979;36(1):44-5.

40. Thal LJ, Sharpless NS, Wolfson L, Katzman R. Treatment of myoclonus with L-5-hydroxytryptophan and carbidopa: clinical, electrophysiological, and biochemical observations. Ann. Neurol. 1980;7(6):570-6.

41. Budhram A, Lipson D, Nesathurai S, Harvey D, Rathbone MP. Postanoxic Myoclonus: Two Case Presentations and Review of Medical Management. Arch. Phys. Med. Rehabil. 2014; 95: 588-90. 